\title{
The Mirror Cracked: symmetry and refinement in the Acheulean handaxe.
}

John McNabb ${ }^{1}$ and James Cole ${ }^{2}$.

1. Department of Archaeology, University of Southampton, Southampton, SO17 1BJ, UK.

scarab@soton.ac.uk. Corresponding author.

2. University of Brighton, School of Environment and Technology, Moulsecoomb, Brighton, BN2

4GJ, UK. J.N.Cole@brighton.ac.uk

\begin{abstract}
.
The Acheulean is a stone tool industry that originates in Africa over 1.7 mya. It is characterised by the bifacially shaped handaxe as part of a group of tools commonly referred to as LCTs - large cutting tools. Traditionally, the Lower Palaeolithic/Early Stone Age Acheulean is seen as continuing throughout much of the Old World until c. 0.25 mya and the advent of the Middle Palaeolithic, though handaxe usage continues well after this. At least two different hominin species are responsible for making handaxes across this time span, $H$. ergaster/erectus, $H$. heidelbergensis. It is possible that the earliest $\mathrm{H}$. sapiens in Africa also made and used handaxes. A long running debate concerns whether or not there is an evolution in Acheulean material culture. This involves the belief that handaxes and other LCTs become more refined and sophisticated as time goes by. There are two schools of thought on this. The first argues that advances in Acheulean material culture march in lockstep with brain and cognitive evolution, while the second sees a mismatch between them. In this latter scenario material culture falls behind cognitive evolution. We argue that the key to understanding Acheulean material culture is variability and that symmetry and refinement in handaxes are likely to be situational/local. No long term trends are visible in the archaeological record which show an increase in refinement or handaxe symmetry. We suggest a 'variable equilibrium' model to explain the patterns seen and show how the archaeology maps onto similar biological interpretations.
\end{abstract}

\section{Keywords.}

Handaxe, Acheulean, LCT, cognition, hominin, social brain, theory of mind, intentionality, symmetry, refinement, biface, hominin evolution.

\subsection{Introduction.}

Recently, Derek Hodgson (Hodgson, 2015) reviewed the current state of the debate concerning the evidence for an evolution in the material culture of the Acheulean, in particular concentrating on that techno-complex's iconic artefact, the handaxe. Readers of J.A.S.: Reports, unfamiliar with the debate, might be forgiven for thinking that Hodgson's enthusiastic presentation reflected a series of inter-related research questions that were no longer in any doubt; namely that an evolution in Acheulean material culture was a proven phenomenon, and that handaxes become more refined and more symmetrical over time. The reality of the case is less clear.

Hodgson's paper presents a timely opportunity to briefly review some of the main arguments used in the symmetry debate. Its context has been briefly outlined in the abstract and need not be enlarged on here. In this short paper we will firstly critique a selection of the literature on handaxe symmetry, using Hodgson's paper as a spring board. Secondly, we present our view on the 'tempo of 
brain evolution' (sensu Shultz et.al. 2012) in hominins. This sets the context within which Acheulean materiality can be discussed. Thirdly, we will present our own quantitative data for symmetry and refinement in handaxes. Finally, we will review some of the ideas from the Social Brain (Dunbar, 1998; Dunbar, 2003) hypothesis which is used as a context for evolving hominin materiality in the Acheulean.

\subsection{Interpretations of handaxe symmetry.}

Hodgson (ibid) presents a useful review of some of the more important literature cited in discussions of handaxe symmetry and refinement. The purpose of this section is to show that despite statements to the contrary, much of this literature does not actually establish the existence of an evolution in handaxe refinement as it is often claimed to do.

Saragusti and colleagues (Saragusti and Sharon, 1998) trialled an assessment of symmetry in handaxes by pioneering a method that generated a mathematical nearest fit model to the outline of the actual handaxes - the continuous symmetry measure. While their data did find a progression in Israeli sites from the earliest handaxes at 'Ubeidiya (1.4 mya), through the later assemblage at Gesher Benot Ya'aqov (>0.78 mya), to the undated Later Acheulean handaxes from Ma'ayan Barukh, (its age was only established on typological grounds), the authors, with commendable scientific honesty, were quite clear that their data fell below the 'routine requirements for statistical analysis' (ibid 822). The sample comprised only three sites, and LCT numbers were small ( $\mathrm{N}=8$ for the last named site).

Subsequently, handaxes were again incorporated into a new measure of shape analysis by Saragusti et al. (Saragusti et al., 2005). This increased the sample sizes from each of the three original sites, and added two new assemblages from different layers in the Tabun cave. Layer 90 is considered older than layer E dated to c. 0.35 mya (Gisis and Ronen, 2006; Matskevich, 2006), and the implication is that both Tabun levels post-date Ma'ayan Barukh. The authors record their surprise that the while the pattern of the first analysis is repeated for the three original sites, the asymmetry values for the more recent Tabun levels show a return to the higher values more closely associated with Ubeidiya and GBY. These well designed and executed analyses make it clear that identifying development in Acheulean material culture over time is not a straightforward task. Another Israeli study is that of Grosman and colleagues (Grosman et al., 2011). Despite an enthusiastic defence and an intriguing methodology, the assemblages used in the study are all surface finds which cannot be unambiguously associated with the deposits they are said to come from.

Work by Goren-Inbar and Sharon (Goren-Inbar and Sharon, 2006; Sharon and Goren-Inbar, 1999) is mentioned by Hodgson (ibid) in the context of a '...trend towards more refined standardised tools from Early to Late Acheulean...' (Hodgson 2015, 205). Neither of these papers deals directly with this subject. In their 2006 paper these authors address the complexity and variability present at Acheulean sites. Their 1999 paper does mention the longstanding belief that the difference between the Early Acheulean and the Middle Acheulean was the introduction of soft hammer thinning. This is a somewhat old fashioned concept now, and was particularly popular in the 1960s and 1970s in the UK. The Gesher Benot Ya'aqov data (ibid 1999) demonstrates the possibility of soft hammer flaking dating, at the very least, to the Early/Middle Pleistocene boundary. These authors also cite experimental work (Bradley and Sampson, 1986) which shows that the scar pattern and character of thinning, as it manifests itself on flint axes, can be reproduced with hard hammers as well. Roughly flaked hard hammer bifaces can be found in any number of sites that post-date the EP/MP boundary and occur squarely within what would have been classed as Middle Acheulean times (UK examples from Kent's Cavern, Fordwich and Farnham Terrace A spring to mind. These were once thought of as 
pre-Anglian (MIS 12) Acheulean sites on the basis of their 'crude' hard hammer flaking - some examples from the post-Anglian Middle Gravels at Swanscombe would also qualify (McNabb, 2007; Roe, 1981)). Indeed, Sharon and Goren-Inbar (1999) cite Francois Bordes' suggestion that soft hammer flaking at Cagny la-Garenne dated to the Early Acheulean as then conceived.

Concepts of a progressive early, middle and late development in the Acheulean reached their apogee before the second world war and remained popular until the late 1940s and early 1950s (Breuil, 1932; Breuil, 1939; King and Oakley, 1936; Paterson, 1940-1941; Paterson, 1945; Swanscombe Committee, 1938). The belief in diachronic global-scale stages of development ensured that such sequences could be applied anywhere where Palaeolithic archaeology was found (Leakey, 1951; Movius, 1948; Underhill, 2011; Van Riet Lowe, 1937; Van Riet Lowe, 1952a; Van Riet Lowe, 1952b). Despite a pervasive dissatisfaction with the typological approach from the 1960s onwards, the concept of evolutionary development in the Acheulean was recycled by a new generation of archaeologists following new analytical procedures, who nevertheless did not question the underlying truth of a typologically generated belief in progressive cultural evolution (Mason, 1962; Roe, 1964; Roe, 1968; Wymer, 1961; Wymer, 1968). The concept continues to find supporters amongst more recent researchers (Kuman, 2007; Leakey and Roe, 1994). At the end of the day the belief in a progressive early middle and late Acheulean has never been tested against a large robust data set of well dated and contextualised assemblages.

New approaches to the question of development within the Acheulean have not always clarified the matter. Couzens work is instructive in this respect (Couzens, 2012). Pioneering a distinctive 3D scanning approach, this author's data actually shows remarkably little difference between handaxes from the South African site of Rietputs 15 (1.4 mya) and the Cave of Hearths (c. 0-5-0.3 mya). Couzens highlighted this, and raised the issue of variability within the two assemblages noting the influence of raw material, and particularly, blank form on handaxe finish. This reference flags a clear issue in these kinds of study, one that is explicitly acknowledged by the author. Only two sites are examined. Both sites demonstrate a significant emphasis on flake blanks $(58 \%$ and $>70 \%$ respectively). To argue that there is a progression toward more refined axe working on the basis of only two sites is somewhat premature (Hodgson 2015). Couzens himself suggests the difference between the two sites may be functional.

Our reading of Shipton et al.'s thought provoking results from the Son Valley in central India (Shipton et al., 2013) does not coincide with Hodgson's interpretation of a 'seamless' transition between Acheulean and Levallois. The presence of smaller and well refined handaxes in 'Later Acheulean' contexts appears, from the sites listed (ibid p94) to be clear cut, though few dates are provided. However, whether these represent a seamless transition is another thing. The authors' work in the Son valley reveals a series of sites with handaxes, sometimes characterised by unifacial thinning, and recurrent Levallois, normally not present in the local Acheulean repertoire. The date range for these sites would fall between c.100-150kya. This would actually post-date the transition to the Middle Palaeolithic elsewhere, and is reminiscent in age of the handaxes found with Homo sapiens idaltu in Ethiopia (Clark et al., 2003). In fact, one would wonder whether these sites ought to be called Late Acheulean at all? At a neighbouring site to some of those discussed, Nakjhar Khurd, an unambiguous Acheulean assemblage with bifacially worked handaxes is noted to lack any form of Levallois. It has a minimum date of $>100 \mathrm{kya}$, and its distinctiveness in comparison to the handaxe+Levallois Son sites is pointed out by these researchers. Clearly a seamless transition is not present. There is no particular reason why the earliest modern humans could not have been handaxe and Levallois makers - rendering them anatomically but not behaviourally modern. If this were the case then their material culture should not be called Acheulean, despite the presence of LCTs. 
Shipton's work on the assemblages of the Hunsgi-Baichbal Valley, South India (Shipton, 2013) asserts that there is a clear progression in handaxe refinement over time. Shipton's 3D morphometric methodology appears particularly suited to the research questions he addresses, as do the kind of data generated. We would take issue with his work from a methodological standpoint on two aspects only. In performing a cluster analysis on Shipton's data, he clusters according to a generated 'mean' handaxe shape for each site. However, the key point in studies of symmetry and refinement is surely not the measure of central tendency, but an appreciation of the range of variation present we will return to this below. The other issue is with sample size and sample integrity. Shipton's cluster data suggests a chronologically significant tripartite division of assemblages based on his mean shapes, with longer narrower and thicker bifaces gradually becoming shorter, wider and thinner (Shipton 2013, figures 7.1 and 7.2, and p66f). However, three of the six Indian sites used in the cluster analysis ( $n=10$ sites) are undated, and one is a surface assemblage. The sample size from a number of the sites is also very small, in some cases less than 10 LCTs. Once more, to argue an evolution in Acheulean material culture from these data seems premature.

Shipton (ibid) also includes a regression analysis of LCT weight against flake scar count as an indicator of refinement, although details of the samples used are not given. Weight is negatively correlated with flake scar density (his figure 7.7), the former decreasing as the latter increases. Shipton allies this with an increase in refinement and working (his figure 7.8). These data present a strong pattern, and lacking further data of our own, the pattern is difficult to dispute. Exploring the relationship between measures of intensity of working, like flake scar counts, represents a possibly fruitful area of research into refinement analysis and we would urge studies in this direction to take on board blank type (and therefore counting scars on each face separately) and lithology, as well as scaling scar counts for handaxe size.

An increase in LCT refinement is at the core of a stimulating piece by Beyene and colleagues (Bayene et al., 2013) based on fieldwork at Konso in Ethiopia, currently boasting the oldest Acheulean in the world at 1.75 mya. Across a series of six well contextualised and dated sites the authors postulate a local increase in refinement in handaxe manufacturing over time. On the face of it the pattern is convincing, particularly when the illustrations of handaxes are appreciated (their figure 4). Measures of refinement (mean handaxe width/mean handaxe length; mean handaxe thickness/mean handaxe width) are offered for each of the time-successive assemblages. However, Th/W values for handaxes and cleavers (their figure 6) actually show a considerable overlap in the potential range of values present at the site, sounding a warning against a clear progression toward refinement as suggested if only the measures of central tendency are considered (see above in relation to Shipton's work).

The data from Konso given in Beyene et al. (ibid) has been plotted against a series of W/L and Th/W ratios generated for the Acheulean sites in table 1 . The results are shown in figure 1 - since ranges were not given by Beyene et al. this figure has to rely on the mean for a measure of central tendency. The sites date from 1.2 mya down to c 0.25 mya (end MIS 7) and represent a consistent sample of handaxes spanning the later Early Pleistocene and the Middle Pleistocene. Clearly no temporal trend toward smaller and thinner handaxes is apparent in these data. It should however be noted that, as with Shipton's work, Beyene and colleagues show a more convincing trend toward refinement present in the flake scar frequency data as plotted against time.

Hodgson (ibid) highlights the work of Machin (Machin, 2009; Machin et al., 2007) in demonstrating that symmetry as a measure of increasing refinement is allied to an emerging sense of aesthetic, since it confers no functional advantage in handaxe use. Machin and colleague's experiments (2007) actually showed that symmetry did improve some aspects of carcass butchery, but the relationships were statistically weak. While planform symmetry did not materially aid the overall ease with which 
a carcass could be dismembered, edge symmetry (which we take to mean a relatively straight and consistent cutting edge) may be more important. Machin does indeed state that symmetry may have become more important as a non-utilitarian factor in the performance of making a socially significant tool, the handaxe; her ideas are embedded within the development of a model that suggests visual performance itself becomes more important for $\mathrm{H}$. heidelbergensis as a reflection of life history changes. An emerging sense of aesthetic is implicated in the importance of visual display (see also the Visual Display Hypothesis (McNabb, 2012) for similar). But Machin's multi-factorial model is quite specific in its emphasis of the complexity and multi-facetted nature of the influences on individuals making handaxes. She is quite clear that no one answer explains handaxes, or, the key variability seen in assemblages that she rightly emphasises. For handaxes this is a 'must read' paper.

The question of variability within assemblages is a key one. Machin rightly emphasises it, as did Couzens and Goren-Inbar and Sharon (above), and we have noted the difficulties that may be present in focusing only on measures of central tendency. The data for figure 1 was presented in table 1 . The same database of assemblages and samples is presented in figure 2 where refinement is explored through the maximum and minimum values of the total range (the median is here presented as a measure of central tendency). $\mathrm{W} / \mathrm{L}$ and $\mathrm{Th} / \mathrm{W}$ are common indices of refinement in a number of studies - the drift to lower values in their central measures being taken as an indicator of ever increasing refinement over time. However, the range represents the total spread of variability in an assemblage, actually reflecting the range of what was possible and what was acceptable to the handaxe makers in that assemblage. In terms of handaxes getting smaller over time, $\mathrm{W} / \mathrm{L}$ - figure $2 \mathrm{a}$, these data do not support a general trend in that direction. It is very clear that there is considerable overlap in the diversity of refinement in this measure from the million year old site of Doornlaagte in South Africa to the Achello-Yabrudian levels of Tabun E. There are mixed signals from the Th/W values in figure $2 \mathrm{~b}$. The MCT for the South African sites does show a drift toward thinner and wider axes, but again there is huge overlap between the sites in this measure of refinement, and the Fauresmith sites from Kimberley (Beaumont and Vogel, 2006) are on hornfels a fine grained raw material which lends itself very well to thinning and shaping (JM personal observation). The c. 800 kya Bed IV site (McNabb, 2005) at Olduvai Gorge (HK) almost spans the whole of the range seen in all the South African sites, while the British sites reverse the South African trend with an equally impressive range of acceptable levels. Certainly these measures of refinement don't support a trend toward more refined handaxes over the duration of the Acheulean.

For many archaeologists alarm bells will already be sounding as assemblage integrity, time averaging and palimpsests begin to rear their ugly but necessary heads. We are conscious of these concerns, but note that this is exactly the kind of data that is being used to pursue this debate. The issue of assemblage range is also pertinent to Hodgson's (ibid) remarks on the MIS 8/7 site of Cuxton in the UK, where Francis Wenban-Smith (Wenban-Smith, 2004; Wenban-Smith, 2006) recovered an impressively large ficron handaxe (sensu UK, elongated with concave sides). Hodgson describes it as exquisite and the craftsmanship as flamboyant. This is an individual knapper, recognising his or her skill and revelling in it, though from a knapper's perspective, ebullience may have been tempered by relief at not breaking such a long handaxe. Equally impressive handaxes in the same style, but not as big, were recovered from the earlier Tester excavations at the site (Tester, 1965).

The skill and spectacular finish of these handaxes is not in question. But extracting them from the remainder of the other axes from the site encourages a false perception of the assemblage as a whole and over emphasises the importance of these individual axes. A sub-sample of 50 Cuxton handaxes from the Tester excavation were identified through random number generation from the Marshall et al. database (Marshall et al., 2002). They were subjected to a symmetry analysis 
following the basic methodology outlined in McNabb 2013 (McNabb, 2013). The method is briefly summarised in the legend to figure 3 as are changes to the 2013 methodology made for this paper.

The data are presented in figure 3. Firstly the outlines of the 50 axes analysed (inset to figure) make it very clear that while a small number are similar to Wenban-Smith's flamboyant ficron (marked as 1 and 2 on the figure), the majority are not. This MIS 8/7 site shows a variety of outline shapes. Secondly, the symmetry values reflect the variation shown in the outlines (and in the refinement values in figures $2 a$ and $2 b$ on a larger sample). There is a gentle graduation from handaxe 541 on the left hand side of the $X$ axis to handaxe 380 , whereupon the symmetry values become markedly more asymmetric as the axe outlines in the bottom right of the inset would suggest. In other words a range of values covering a few of the skilfully made elongated axes, as well as the remaining more mundane examples - certainly not an assemblage whose overall character reflects the refinements seen in a few of its axes. This pattern is echoed through two larger datasets of 1838 and 2680 handaxes from a predominantly British Lower to Middle Palaeolithic sample (spanning MIS $13-3$ ) seen by Cole (Cole, 2011; Cole, 2015; Cole, In press) using the methodology developed by McNabb (McNabb et al., 2004; McNabb and Sinclair, 2009).

The key point here is that LCTs should not be extracted from the range of variability present in the parent assemblage as a whole. It is the total range of variation (in symmetry, refinement as well as form) that characterises an assemblage, not isolated aspects of it. Prehistorians have long rejected the fossil-director approach of the Abbe Breuil and the 1930s (Breuil, 1939; Breuil and Koslowski, 1932) where by an assemblage was characterised by a small number of the best made pieces, in favour of assessments which were more inclusive and assemblage based (Bordes, 1961). This is not a trend that should be reversed.

In questioning whether refinement in Acheulean material culture increases over time, all we have ever asked for is that the debate be rooted in robust data (a large number of sites which are well contextualised, good chronological control, large samples and a proven methodology consistently applied). We recognise this is a tall order.

\subsection{Timing and tempo in hominin brain evolution ${ }^{1}$.}

It is common in graphs showing the evolutionary development of the brain to take the mean brain size of different hominin species, as a measure of central tendency and plot the results against time. The sloping line that results from this is usually presented as a smooth and unbroken gradient. This powerful visual image, taken as a representation of cognitive evolution, lies at the heart of the belief that social and biological evolution proceed hand in hand.

Shultz and colleagues (Shultz et al., 2012) argue that the data is better visualised and interpreted as a series of steps rather than an incremental slope. Their data is presented through a series of box and whisker plots and takes on board the variability inherent in the hominin data set between species. This conclusion, and the method of presentation, was originally suggested to the Social Brain project by ourselves, though we used a different data set to Shultz et al., and did not link it to climate data to illustrate that climatic forcing cannot be recruited as a major driver in brain expansion. The conclusion of Shultz et al. (ibid) is that there have been long periods of relative stasis in brain expansion, punctuated by step changes. They argue for major steps occurring at 1.9 and 1.8 mya with the appearance of $\mathrm{H}$. habilis and $\mathrm{H}$. ergaster (early $\mathrm{H}$. erectus) respectively. More recent work on $\mathrm{H}$. habilis (Spoor et al., 2015) suggests an age greater than 2.3 mya for this species while flagging up considerable uncertainty in its true phylogenetic character. There was some evidence for 
a gradual increase in brain size between early and later erectines in Africa. A third step occurs between 0.4 and 0.2 mya ago - within the time frame of $H$. heidelbergensis, possibly associated with the heidelbergs migrating out of Africa; otherwise, there is long term stasis within the heidelbergs. Finally, at 0.1 mya there is a step change within the time frame of H.sapiens, probably co-incident with the emergence of language (Bolhuis et al., 2014; Fitch, 2010; McMahon and McMahon, 2013).

Here we have extracted from Shultz et al's data the relevant information for the handaxe making hominins $H$. ergaster, $H$. erectus, $H$. heidelbergensis and earliest $H$. sapiens in Africa who appear to be associated with a middle Palaeolithic technology and handaxe manufacture (Clark et al., 2003; Van Peer et al., 2003; Vermeersch, 2001; Vermeersch et al., 1998). Following Shultz et. al.'s suggestion of breaking the data up by region, we re-present their data in table 2 and figure 4a. The step-and-stasis character to brain expansion is evident from the figure. Using less complicated statistical treatments than that of Shultz et al., there is a weak statistical difference between $\mathrm{H}$. ergaster and the later Asian erectines, a strong statistical difference between the Asian erectines (and by implication the African ones too but the sample is too small for certainty) and the heidelbergs, and a statistically significant difference between them and the earliest $H$. sapiens in Africa. If a straightforward species only comparison is conducted, ignoring geography, the same stepwise pattern and statistical differences are noted (data not presented).

But how static is stasis? It is also clear from the data in table 2 that there is considerable variability in absolute brain size between individual specimens, even within geographically distributed species groups, let alone on a species only basis. This is shown clearly in figure $4 \mathrm{~b}$. These data then underscore the step-and-stasis model by showing that the step changes, when they occur, lift the majority of the new range of brain size variability (expressed by the interquartile range) out of that of the range of the lower/older phase. Evidently, there was a great deal of between-individuals variability within each species (and presumably within individual populations too). So a step-andstasis visualisation of brain expansion in hominins becomes a 'punctuated variable-equilibrium' model.

We have tried to visualise this in the schematic in figure 5 . We believe this is the best way of understanding brain expansion in hominin evolution, and it is the lens through which Acheulean material culture and its variability should be explored.

\subsection{Handaxes and cognitive implications.}

In the preceding section we supported Shultz et al's (2012) contention that the pattern and tempo of hominin brain evolution was best interpreted as a stair case rather than an unbroken slope, coining the expression 'punctuated variable-equilibrium' to describe the variation in absolute brain sizes present along each horizontal step (figure 5). The graphic of an unbroken slope underpins most views of evolution and is central to the social brain hypothesis that Hodgson (ibid) draws on to suggest that Homo heidelbergensis had cognitive capacities which approached those of modern humans, thus providing the cognitive underpinning to explain why and how it was that Acheulean material culture could have complex social meanings for its makers. This is a key point.

The primary starting point is theory of mind and orders of intentionality and their relation to different hominin species (Dunbar, 2004; Dunbar and Shultz, 2007; Gamble, 2015; Gowlett et al., 2012). We will not go into an explanation of theory of mind here, or of the hierarchical ordinal scale of intentionality orders as this has been done by Hodgson (ibid) and others on a number of occasions (Baron-Cohen, 2001 ; Dunbar, 1998; Dunbar, 2004; Premack and Woodruff, 1978). Here we will just 
remind readers that intentionality level $2=$ a full theory of mind, and that this incorporates the ability to comprehend the mental state of one's own mind, and that of another, as well as recognise that the mental state of the other's mind may differ from one's own. Following the predictions of the social brain hypothesis, Hodgson accepts a level 4 order of intentionality for Homo heidelbergensis (Gamble, 2015), arguing that the identity model developed by James Cole (Cole, 2011; Cole, 2012; Cole, 2014) requires that $3^{\text {rd }}$ order of intentionality is a minimum requirement to incorporate material culture within visual displays to mediate social relationships and imagine a fictitious world facilitated by a "detached" visually disposed imaginative faculty (Gowlett et al., 2012). Indeed, as hominins come to consciously engage with a $3^{\text {rd }}$ order of intentionality the signs of such ability should be discernible within the archaeological record where artefacts could be used as social proxies in (for example) marking territory (Pope et al., 2006) and in iconic social signals (Shipton, 2013) compatible with a raised concern for symmetry during the Late Acheulean (Hodgson ibid).

The claim that Homo heidelbergensis has a $3^{\text {rd }}$ or $4^{\text {th }}$ order of intentionality is related to the predictions of the social brain hypothesis based on brain size and predicted group size. It is worth emphasising that predicted group size is extrapolated from the relationship between group and brain size in anthropoid primates. Currently there is no viable independent test for these predictions as they relate to hominins as the authors of the social brain admit (Shultz et al., 2012). Elsewhere we have independently suggested that when the social brain's cognitive predictions are compared against the behavioural markers of the archaeological record, there would appear to be a lag between the predicted and realised orders of intentionality (Cole, 2011; Cole, 2015; McNabb, 2012; McNabb, 2013). Or in other words, having the potential, and realising that potential are not always the same thing. Therefore it has been suggested that the social brain predictions are best seen as markers of maximum cognitive potential, whilst the archaeological record when examined through Cole's identity model allows an assessment of the realised order. This in turn suggests that biological changes need to occur (increase in brain size) before behavioural changes are evident within hominin development (Cole ibid). Although there are of course issues with this approach, at a species level it would appear that $H$. heidelbergensis falls comfortably within the $2^{\text {nd }}$ order bracket with the intermittent potential for $3^{\text {rd }}$ order intentionality.

Why is $\mathrm{H}$. heidelbergensis a minimum of $2^{\text {nd }}$ order though? There is clearly a range of handaxe forms present across all the datasets discussed here, yet all the artefacts are recognisably handaxes. There therefore must be some 'conceptual standardisation' (McNabb et al., 2004) in handaxe form that would indicate an ability to conceive in the mind's eye a specific abstract idea like a handaxe, yet whose finished form/appearance was negotiable - the mental construct of McNabb and Ashton (Ashton and McNabb, 1994). To engage with a mental construct or conceptual standardisation clearly implies that the handaxe knappers had a theory of mind or $2^{\text {nd }}$ order intentionality at a minimum - handaxes are examples of abstract thought. Since hominins learnt how to make handaxes in a social environment, at the very least they had to recognize the 'other's' intentions in order to framework their own as they learnt. The very act of making and using handaxes in social contexts implies and requires a theory of mind. The key point here is that it does not require third order or above. It is quite conceivable that complex social relations can exist in societies that do not progress beyond a theory of mind (many social predators - hyenas, lions, hunting dogs - have complicated hierarchical group structure yet do not possess a theory of mind).

There is a methodological issue here as well. Hodgson states that orders of $3^{\text {rd }}$ to $4^{\text {th }}$ orders of intentionality approach the $5^{\text {th }}$ order present within Homo sapiens. Although this statement is not 
incorrect, it is somewhat misleading and does not fully acknowledge the fact that the orders of intentionality are an ordinal scale where the levels of cognitive complexity increase exponentially. Through such an ordinal scale it is clear that a great deal of cognitive and social complexity can be imparted even if only a small number of different belief/mental states are linked together (Premack and Woodruff, 1978). Therefore the notion that a $3^{\text {rd }}$ to $4^{\text {th }}$ order of intentionality is close to a $5^{\text {th }}$ order of intentionality is not so straightforward, and much further apart cognitively than Hodgson seems to suggest. We have provided more detail and examples on this elsewhere (Cole, 2011; Cole, 2014; Cole, 2015; Cole, submitted; McNabb, 2012).

However, this is not to say that the heidelbergs were not cognitively complex. A theory of mind and possible $3^{\text {rd }}$ order intentionality is not to be taken lightly and there is a great deal of cognitive complexity encapsulated within 3 levels of intentionality. $3^{\text {rd }}$ order is the minimum requirement for symbolic communication using material culture (Cole, 2015), it is just not as complex or imaginatively liberating as $5^{\text {th }}$ order which is often seen as the minimum for supernatural concepts (Dunbar, 2004)

As Hodgson suggests, and we agree, once hominins start to actively and consciously engage with a $3^{\text {rd }}$ order of intentionality this ought to be evident within the archaeological record, a point covered in more detail through the visual display hypothesis and the identity model (McNabb 2012; Cole op cit.). But this relies on a realised capacity for level 3 being sustained and fixed permanently within social groups. Symmetry, as a proxy for cognitive advancement, could be taken to reflect the realisation of $3^{\text {rd }}$ order potential if it was dominant (not just present) in an assemblage of handaxes. Where we disagree with Hodgson is the point at which this is seen in the archaeological record. From the data we have engaged with here and elsewhere, we have shown that symmetry, while often present, does not form a major component of most of the Early or Middle Pleistocene assemblages so far studied (usually $<10 \%$ ). The span of time present in figures 1 and 2 , and the MIS $8 / 7$ date for Cuxton, figure 3, suggest that there is no broad increase in symmetry over the time period of $\mathrm{H}$. heidelbergensis, and that refinement (as measured in figure 2 ) is variable over that period. The only convincing exception to this is Boxgrove (Roberts and Parfitt, 1999). Perhaps here, a tightly knit social community, lasting over little more than three generations, did achieve a sustained third order. ${ }^{2}$

Thus, if level 3 intentionality is a minimum requirement for successful social signalling, and symmetry and refinement can indeed be taken as proxies for level 3 , then the data suggests the following. Firstly, some individuals may achieve level 3, but the remainder of their social group do not, as perhaps at Cuxton. Secondly, occasionally a small social group may attain this level as at Boxgrove (or at least the knappers within it assuming not everyone made handaxes), but it does not have an effect at species level. What is interesting here is why these innovations at individual or group level do not persist - possibly small group sizes with weak or fragile social networks between groups (Gamble, 2013) are not capable of sustaining cultural innovation stemming from temporally isolated cognitive shifts. The result is local extinction and the persistence of the species base line.

But there are other ways of looking at the symmetry problem. Even if a group of handaxe makers did achieve a standardised end product, it doesn't necessarily imply they had to be signalling with it. Perhaps Acheulean hominins did not view standardisation or the imposition of symmetry on tool form in the same way that modern humans do, indeed why would they? These ancient hominins had brains that were shaped and wired differently to ours and were smaller, and the environments that 
shaped their life-ways were dramatically different to our own. Therefore it may well be unfair of us to assume, even for a hominin of intentionality level 3, that symmetry or standardisation in artefact production should play a significant role in hominin social signalling when we are dealing with nonhuman species whose views of the world and their position in it would be drastically different to ours. Although this explanation will leave many feeling unsatisfied, it is an important point to raise and be considered.

Finally, Hodgson refers to the giant handaxes from a number of sites, making the point that like the flamboyant Cuxton pointed handaxes these giants are over engineered, clear proof for Hodgson of evolving cognitive faculties. Giant handaxes such as those at Cuxton in UK, and Isimila in Tanzania (Howell, 1955; Van Riet Lowe, 1951; Wenban-Smith, 2004) do indeed throw up the intriguing prospect of the ways in which some artefacts within assemblages may carry more social weight than others - they are simply too large to be seen as purely functional tools (at least from a modern perspective). However, even with these seemingly "extraordinary" artefacts it should be noted that the exact role of the so-called giant handaxes and their place within wider Acheulean assemblages remains unclear and it is by no means certain that they were truly artefacts used to mediate social relationships. This is due largely to the fact that many are isolated surface finds (Kelley, 1959), and so lacking a clear context within an assemblage or time period, their role within hominin societies remains more speculative than certain and in need of further work .

\subsection{Conclusion.}

Hodgson's ultimate contention is that as the hominin brain evolves new neural pathways evolve for transferring information from the centres of perception to those involved in processing and understanding information. New pathways forge new connections and greater connectivity provides a platform for greater innovation and advancement in cognition. Effectively the evolution of the modern brain. We make no comment on this. Sadly direct evidence for this process cannot be preserved and so brain scientists must look for proxy data to support this. The Acheulean lasts for well over a million years and it is across this time span and hominin range that we should see a gradual advancement in material culture paralleling biological development. Hodgson argues we do, we argue it might be so, but the data to prove it is not there yet. Archaeological data are contextually nuanced, remove the data from its context, either physical or methodological, and it can be gifted with a meaning that is illusory.

Symmetry and refinement are clearly present in the handaxe record, they occur in individual axes as well as occasionally at an assemblage level. What we do not see is a gradual shift from sporadic occurrences within assemblages, to assemblages dominated by them. In other words, no gradual slope of advancement in material culture in the Acheulean. Rather, we suggest, as with Shultz and colleagues, that the hall mark of the Acheulean is variability, seen within long periods of apparent stasis - what we have here termed variable equilibrium within a step-and-stasis model. Figure 6 is a schematic illustration of this developed from figure 5 , and expresses the notion that variable equilibria apply to both biological and social/archaeological data too.

We desperately need better dated Acheulean sites, and more of them, and we need to apply a robust method of assessing refinement and symmetry to these sites. With the appropriate data it may well be then that we see symmetry and refinement increase over time and Hodgson and colleagues contentions vindicated. If so then fine, the beer is on us! Until that time we must be cautious about the data we use, and the way in which we use it. 
Note

1. We are conscious that in this article we have ignored the Neanderthals who were handaxe makers in northern/central Europe. Our justification for this is that we are not discussing human evolution in general, only that part of it concerned with the Acheulean.

2. We are currently developing a measure of symmetry to apply to the British database of Acheulean sites. A preliminary conclusion of this work is that ovate type handaxes, such as Boxgrove, may well lend themselves to greater degrees of symmetry by their very nature, and the fact they are made on good quality flint.

\section{References}

Ashton, N., McNabb, J., 1994. Bifaces in perspective. in: Ashton, N., David, A. (Eds.), Stories in Stone. Lithic Studies Society Occasional Paper 4. The Lithics Studies Society, Oxford, pp. 182-191.

Baron-Cohen, S., 2001 Theory of mind in normal development and autism. Prisme 34, 174-183.

Bayene, Y., Katoh, S., WoldeGabriel, G., Hart, W.K., Uto, K., Sudo, M., Kondo, M., Hyodo, M., Renne, P.R., Suwa, G., Asfaw, B., 2013. The characteristics and chronology of the earliest Acheulean at Konso, Eithiopia. PNAS 110, 1584-1591.

Beaumont, P., Vogel, J.C., 2006. On a timescale for the past million years of human history in central South Africa. South African Journal of Science 102, 217-228.

Bolhuis, J.J., Tattersall, I., Chomsky, N., Berwick, R.C., 2014. How could language have evolved? PLoS Biology http://journals.plos.org/plosbiology/article?id=10.1371/journal.pbio.1001934; Accessed 26/05/15.

Bordes, F., 1961. Typologie du paleolithique ancien et moyen. Delmas, Bordeaux.

Bradley, B., Sampson, C.G., 1986. Analysis by replication of two Acheulean artefact assemblages. in: Bailey, G.N., Callow, P. (Eds.), Stone Age Prehistory. Cambridge University Press, Cambridge, pp. 2945.

Breuil, H., 1932. Les industries a éclats du Paléolithique ancien, 1. - le clactonien. Préhistoire 1, 125190.

Breuil, H., 1939. The Pleistocene succession in the Somme valley. Proceedings of the Prehistoric Society 5, 33-38.

Breuil, H., Koslowski, L., 1932. Études de stratigraphie paléolithique dans le nord de la France, la Belgique et l'Angleterre. L'Anthropologie 42, 27-47 and 291-314. 
Clark, J.D., Beyene, Y., WoldeGabriel, G., Hartk, W.K., Renne, P.R., Gilbert, H., Defleurq, A., Suwa, G., Katoh, S., Ludwig, K.R., Boisserie, J.R., Asfawkk, B., White, T.D., 2003. Stratigraphic, chronological and behavioural contexts of Pleistocene Homo sapiens from Middle Awash, Ethiopia. Nature 423, 747752.

Cole, J., 2011. Hominin cognitive and behavioural complexity in the Pleistocene: assessment through identity, intentionality and visual display. Unpublished PhD. University of Southampton.

Cole, J., 2012. The identity model: a method to access visual display within the Palaeolithic. Human Origins 1, $24-40$. http://humanorigins.soton.ac.uk/issues/. Last accessed 04/04/2015.

Cole, J., 2014. Hominin language development: a new method of archaeological assessment Biosemiotics. DOI: 10.1007/s12304-014-9198-8.

Cole, J., 2015. Handaxe symmetry in the Lower and Middle Palaeolithic: implications for the Acheulean gaze in: Coward, F., Hosfield, R., Pope, M., Wenban-Smith, F. (Eds.), Settlement, Society and Cognition in Human Evolution: Landscapes in Mind. Cambridge University Press, Cambridge.

Cole, J., In press. Examining the presence of symmetry within Acheulean handaxes: a case study in the British Palaeolithic. Cambridge Archaeological Journal.

Cole, J., submitted. Accessing Hominin Cognition: Language and social signalling in the Lower to Middle Palaeolithic. in: Wynn, T., Coolidge, F. (Eds.), Formal Cognitive Models in Palaeolithic Archaeology. Oxford University Press., Oxford.

Couzens, R.A., 2012. An analysis of the symmetry of large cutting tools within the South African Acheulean. Unpublished MSc Dissertation., University of the Witwatersrand.

Dunbar, R., 1998. The social brain hypothesis. Evolutionary Anthropology 6, 178-190.

Dunbar, R., 2003. The social brain: mind, language, and society in evolutionary perspective. Annual Review of Anthropology 32, 163-181.

Dunbar, R., 2004. The Human Story. Faber and Faber Ltd, London.

Dunbar, R., Shultz, S., 2007. Understanding primate brain evolution. Philosphical Transactions of the Royal Society Series B 362, 649-658.

Fitch, W.T., 2010. The Evolution of Language. Cambridge University Press, Cambridge.

Gamble, C., 2015. The anthropology of deep history. Journal of Royal Anthropological Institute (NS) 21, 147-164. 
Gamble, C.S., 2013. Settling the Earth: the Archaeology of Deep Human History. Cambridge University Press, New York.

Gisis, I., Ronen, A., 2006. Bifaces from the Acheulean and Yabrudian layers of Tabun cave, Israel. in: Goren-Inbar, N., Sharon, G. (Eds.), Axe Age. Acheulean Tool Making from Quarry to Discard. Equinox Publishing Ltd., London, pp. 137-154.

Goren-Inbar, N., Sharon, G., 2006. Invisible handaxes and visible Acheulean biface technology at Gesher Benot Ya'aqov, Israel. in: Goren-Inbar, N., Sharon, N. (Eds.), Axe Age. Acheulean Tool Making from Quarry to Discard. Equinox, London, pp. 111-135.

Gowlett, J., Gamble, C., Dunbar, R., 2012. Human evolution and the archaeology of the social brain. Current Anthropology 53, 693-722.

Grosman, L., Goldsmith, Y., Smilansky, U., 2011. Morphological analysis of Nahal Zihor handaxes; a chronological perspective. Palaeoanthropology DOI:10.4207/PA.2011.ART53, 203-215.

Hodgson, D., 2015. The symmetry of Acheulean handaxes and cognitive evolution. Journal of Archaeological Science: Reports 2, 204-208.

Howell, F.C., 1955. A preliminary note on a prehistoric donga (Maclennan's donga) in central Tanganyika. The South African Archaeological Bulletin 10, 43-52.

Kelley, H., 1959. Bifaces de dimensions exceptionelles, Monaco. Congres Prehistorique de France, $739-772$.

King, W.B.R., Oakley, K.P., 1936. The Pleistocene succession in the lower parts of the Thames Valley. Proceedings of the Prehistoric Society 2, 52-76.

Kuman, K., 2007. The Earlier Stone Age in southern Africa: site context and the influence of cave studies. in: Pickering, T., Schick, K., Toth, N. (Eds.), Breathing Life into Fossils. Taphonomic Studies in Honour of C.K. (Bob) Brain. Stone Age Institute Press, Bloomington, Indianna, pp. 181-198.

Leakey, L.S.B., 1951. Olduvai Gorge. Cambridge University Press, Cambridge.

Leakey, M.D., Roe, D.A., 1994. Olduvai Gorge Volume V; Excavations in Beds iii, iv and the Masek Beds 1968-1971. Cambridge University Press, Cambridge.

Machin, A., 2009. The role of the individual agent in Acheulean biface variability. Journal of Social Archaeology 9, 35-58.

Machin, A., Hosfield, R., Mithen, S.J., 2007. Why are some handaxes symmetrical? Testing the influence of handaxe morphology on butchery effectiveness. Journal of Archaeological Science 34, 883-893. 
Marshall, G.D., Gamble, C.G., Roe, D.A., Dupplaw, D., 2002. Acheulian biface database. http://ads.ahds.ac.uk/cfm/bifaces/bf query.cfm ADS, York.

Mason, R.J., 1962. Prehistory of the Transvaal. Witwatersrand University Press, Johannesburg.

Matskevich, Z., 2006. Cleavers in the Levantine Acheulean: The case of Tabun cave. in: Goren-Inbar, N., Sharon, G. (Eds.), Axe Age. Acheulean Tool Making from Quarry to Discard. Equinox Publishing Ltd., London, pp. 335-346.

McMahon, A., McMahon, R., 2013. Evolutionary Linguistics. Cambridge University Press, Cambridge.

McNabb, J., 2005. Hominins and the Early-Middle Pleistocene transition: evolution, culture and climate in Africa and Europe. in: Head, M.J., Gibbard, P.L. (Eds.), Early-Middle Pleistocene Transitions: The Land-Ocean Evidence. Geological Society. Special Publications 247., London, pp. 287-304.

McNabb, J., 2007. The British Lower Palaeolithic: Stones in Contention. Routledge, London.

McNabb, J., 2012. The importance of conveying visual information in Acheulean society. The background to the visual display hypothesis. Human Origins 1, 1-23. http://humanorigins.soton.ac.uk/issues/. Last accessed 04/04/2015.

McNabb, J., 2013. Pole to pole. Archaeology and adaptation in the Middle Pleistocene at opposite ends of the Acheulean world. Oxford Journal of Archaeology 32, 123-146.

McNabb, J., Binyon, F., Hazelwood, L., 2004. The large cutting tools from the South African Acheulean and the question of social traditions. Current Anthropology 45, 653-668.

McNabb, J., Sinclair, A., 2009. The Cave of Hearths: Makapan Middle Pleistocene Research Project: Field Research by Anthony Sinclair and Patrick Quinney 1996-2001. University of Southampton Series in Archaeology Number 1. Archaeopress, Oxford.

Movius, H., 1948. The Lower Palaeolithic cultures of south-eastern and eastern Asia. Transactions of the American Philosophical Society 38, 329-420.

Paterson, T.T., 1940-1941. On a world correlation of the Pleistocene. Transactions of the Royal Society of Edinburgh 60, 373-425.

Paterson, T.T., 1945. Core, culture and complex in the Old Stone Age. Proceedings of the Prehistoric Society 11, 1-19.

Pope, M., Russel, K., Watson, K., 2006. Biface form and structured behaviour in the Acheulean. Lithics 27, 44-57. 
Premack, D., Woodruff, G., 1978. Does the chimpanzee have a theory of mind? Behavioural and Brain Science 4, 515 - 526.

Roberts, M.B., Parfitt, S.A., 1999. Boxgrove. A Middle Pleistocene hominid site at Eartham quarry, Boxgrove, West Sussex. English Heritage.

Roe, D., 1981. The Lower and Middle Palaeolithic Periods in Britain. Routledge and Kegan Paul, London.

Roe, D.A., 1964. The British Lower and Middle Palaeolithic: some problems, methods of study and preliminary results. Proceedings of the Prehistoric Society 30, 245-267.

Roe, D.A., 1968. British Lower and Middle Palaeolithic handaxe groups. Proceedings of the Prehistoric Society 34, 1 - 82.

Saragusti, I., Karasik, A., Sharon, I., Smilansky, U., 2005. Quantitative analysis of shape attributes based on contours and section profiles in artefact analysis. Journal of Archaeological Science 32, 841853.

Saragusti, I., Sharon, I., 1998. Quantitative analysis of the symmetry of artefacts: Lower Palaeolithic handaxes. Journal of Archaeological Science 25, 817-825.

Sharon, G., Goren-Inbar, N., 1999. Soft percussor use at the Gesher Benot Ya'aqov Acheulean site. Journal of the Israeli Prehistoric Society 28, 55-79.

Shipton, C., 2013. A million years of hominin sociality and cognition: Acheulean bifaces in the HunsgiBaichbal valley, India. British Archaeological Reports: International Series. 2468.

Shipton, C., Clarkson, C., Pal, J.N., Jones, S.C., Roberts, R.G., Harris, C., Gupta, M.C., Ditchfield, P.W., Petraglia, M.D., 2013. Generativity, hierarchical action and recursion in the technology of the Acheulean to Middle Palaeolithic transition: a perspective from Patpara, the Son valley, India. Journal of Human Evolution 65, 93-108.

Shultz, S., Nelson, E., Dunbar, R.I.M., 2012. Hominin cognitive evolution: Identifying patterns and processes in the fossil and archaeological record. Phillosphical Transactions of the Royal Society Series B 367, 2130-2140.

Spoor, F., Gunz, P., Neubauer, S., Stelzer, S., Scott, S., A., K., Dean, M.C., 2015. Reconstructed Homo habilis type oh 7 suggests deep-rooted species diversity in early Homo. Nature 519, 83-86.

Swanscombe Committee, 1938. Report on the Swanscombe skull. Prepared by the Swanscombe committee of the Royal Anthropological Institute. Journal of the Royal Anthropological Institute 68, 17-98. 
Tester, P.J., 1965. An Acheulean site at Cuxton. Archaeologia Cantiana 80, 30-60.

Underhill, D., 2011. A history of stone age archaeological study in South Africa. South African Archaeological Bulletin 66, 3-14.

Van Peer, P., Fullagar, R., Stokes, S., Bailey, R.M., Moeyersons, J., Steenhoudt, F., Geerts, A., Vanderbeken, T., De Dapper, Geus, F., 2003. The early to middle stone age transition and the emergence of modern human behaviour at site 8-b-11, Sai Island, Sudan. Journal of Human Evolution $45,187-193$.

Van Riet Lowe, C., 1937. Part ii. The archaeology of the Vaal river basin. in: Sohnge, P.G., Visser, D.J.L., Van Riet Lowe, C. (Eds.), The Geology and Archaeology of the Vaal River Basin. Memoirs of the Geological Survey of the Union of South Africa 35. Geological Survey, Cape Town, pp. 61-131.

Van Riet Lowe, C., 1952a. The development of the handaxe culture in South Africa. in: Leakey, L.S.B., Cole, S. (Eds.), Proceedings of the Pan-African Congress on Prehistory 1947. Basil Blackwell, Oxford, pp. 167-177.

Van Riet Lowe, C., 1952b. The Vaal river chronology. South African Archaeological Bulletin 7, 135-149.

Van Riet Lowe, C., 1951. A new African Acheul stage iv site in Tanganyika. The South African Archaeological Bulletin 6, 94-98.

Vermeersch, P.M., 2001. 'Out of Africa' from an Egyptian point of view. Quaternary International 75, 103-112.

Vermeersch, P.M., Paulissen, E., Stokes, S., Charlier, C., Van Peer, P., Stringer, C., Lindsay, W., 1998. Middle Palaeolithic burial of a modern human at Taramsa Hill, Egypt. Antiquity 277, 475-484.

Wenban-Smith, F., 2004. Handaxe typology and Lower Palaeolithic cultural development: Ficrons, cleavers and two giant handaxes from Cuxton. Lithics 25, 11-21.

Wenban-Smith, F., 2006. Cuxton giant handaxes. Kent Archaeological Society Newsletter 68, 2-3.

Wymer, J., 1961. The Lower Palaeolithic succession in the Thames Valley and the date of the ancient channel between Caversham and Henley, Oxon. Proceedings of the Prehistoric Society 27, 1-27.

Wymer, J.J., 1968. Lower Palaeolithic Archaeology in Britain. John Baker Publishers Ltd., London. 


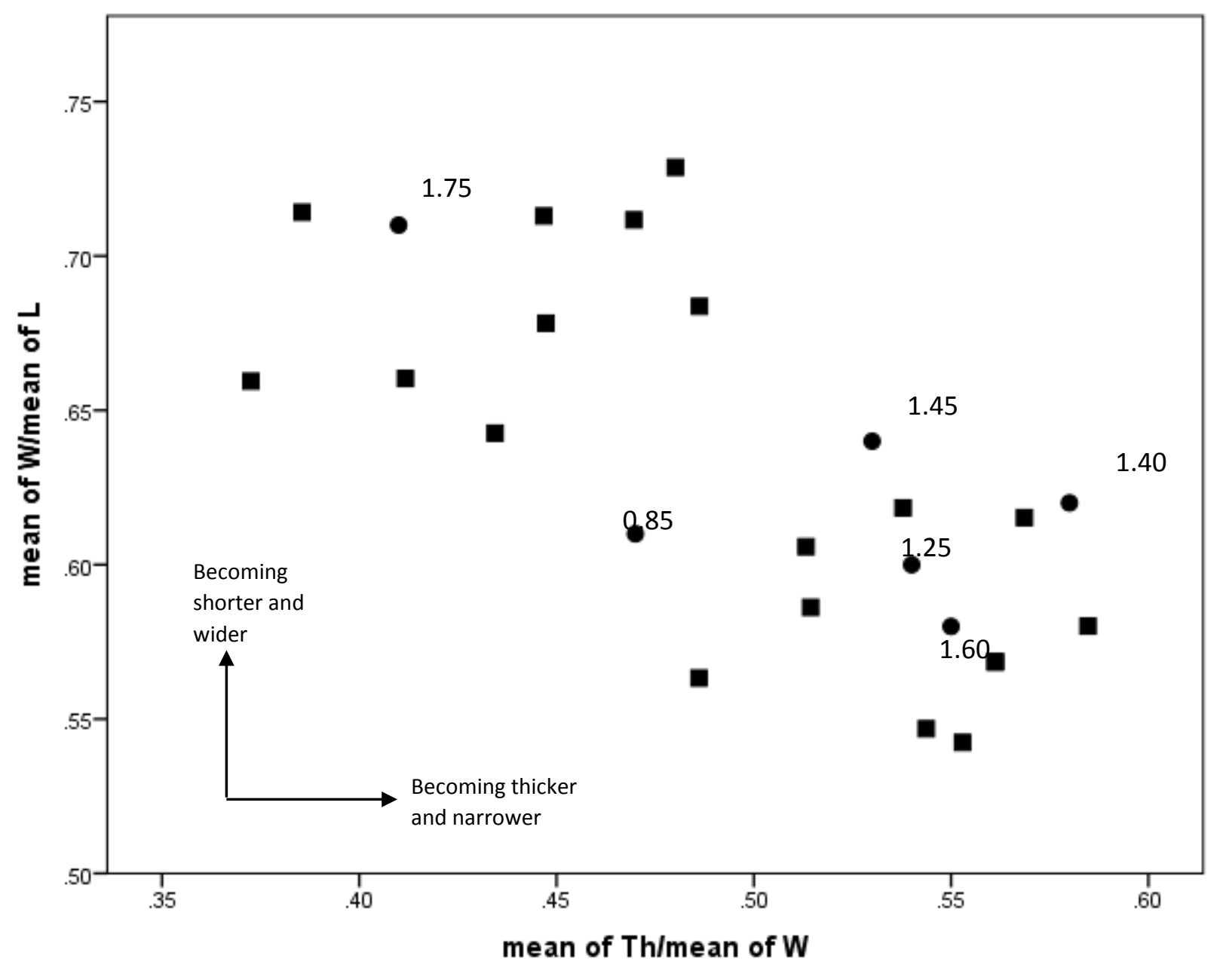

Figure 1. Two measures of refinement plotted against each other. The Konso sites are represented by circles with their respective ages, in millions of years ago, given next to them (after Beyene et al. 2013). Squares represent the sites from table 1 spanning Earlier and Middle Pleistocene ages. The two closest sites to Konso KGA6-A1 at 1.75 mya are Warren Hill lightly abraded (MIS 13) to the left and Bowman's Lodge (MIS 11) to the right. The non-Konso sites are not labelled or dated in order to emphasise how they envelop the Ethiopian localities with in a spread of variability, demonstrating no inherent trend toward greater refinement over time. 
Arrows indicate oldest to youngest

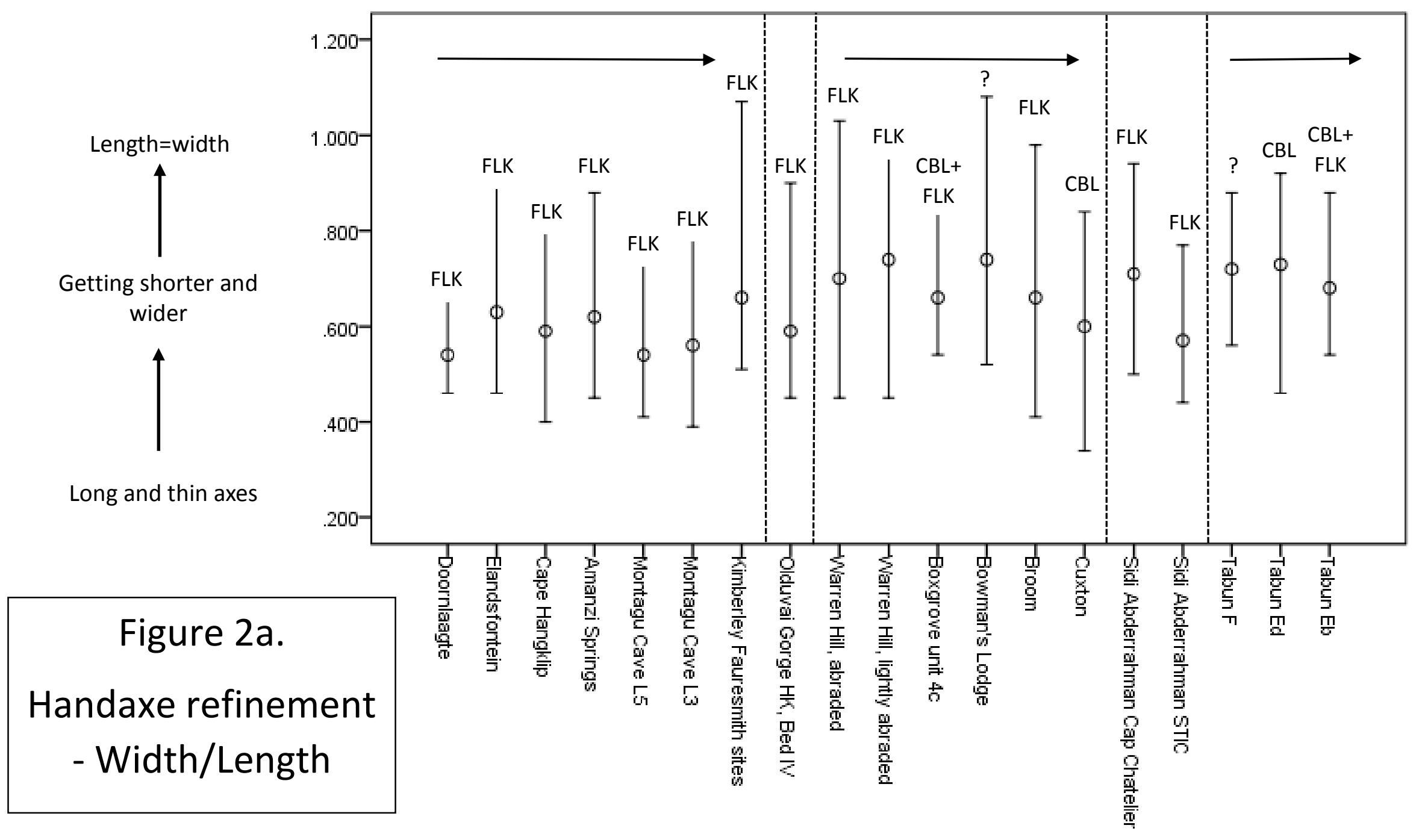

site 
Arrows indicate oldest to youngest

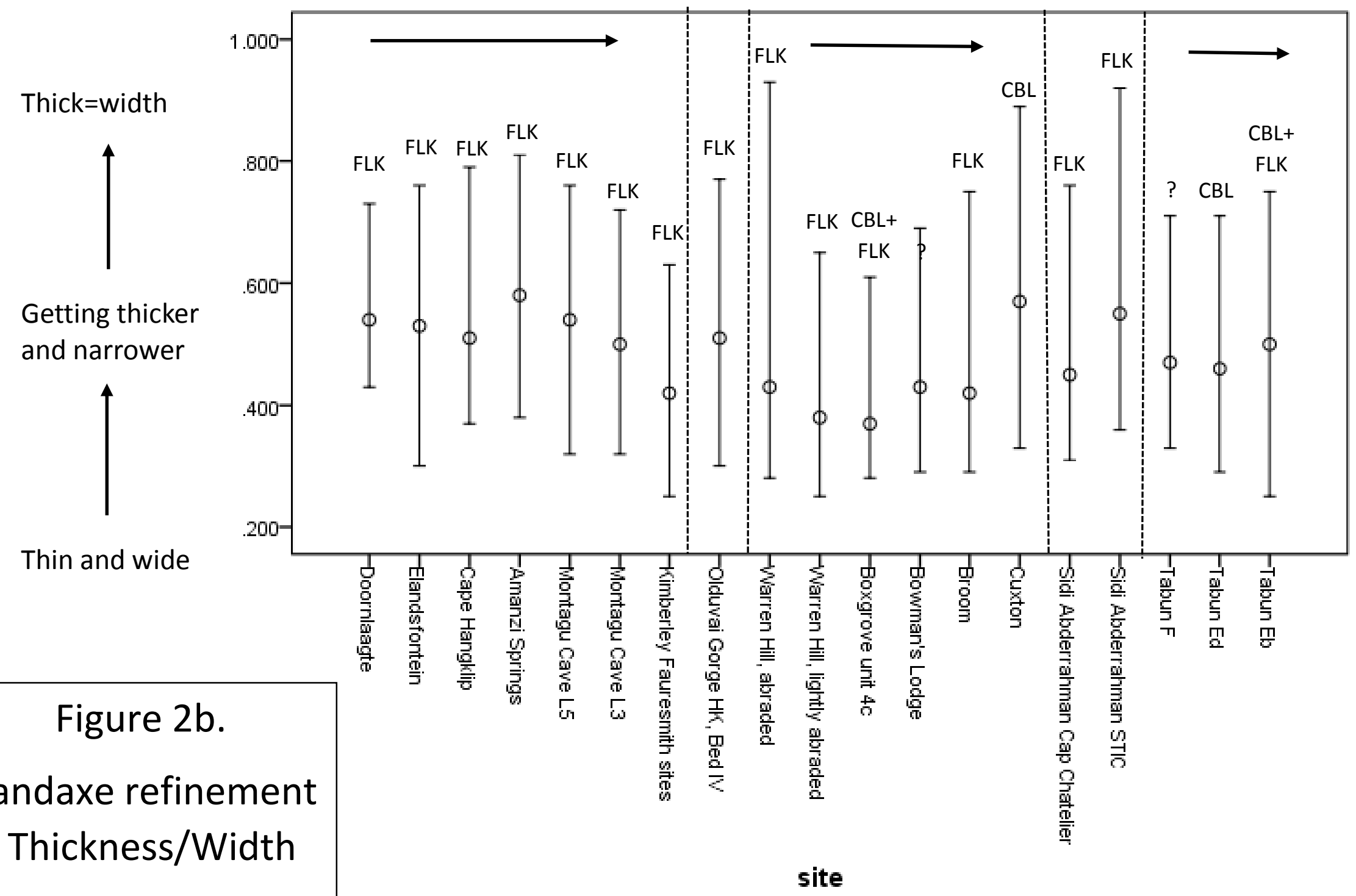


Figure 2. Measures of refinement for handaxes. Figure $2 a-$ index of refinement in planform, width/length. Figure $2 b-$ index of refinement in cross-section, thickness/width. Measure of central tendency is the median. Data taken from 19 assemblages (14 sites) from Marshall et al. database - see bibliography and table 1 for details. FLK - artefacts in this assemblage are predominantly (but not exclusively) made on flake blanks. CBL - artefacts in this assemblage are predominantly (but not exclusively) made on cobble blanks. CBL+FLK - mixture. ? - uncertain. 
Variation in handaxe shape and symmetry on randomly selected handaxes $(n=50)$ from Cuxton

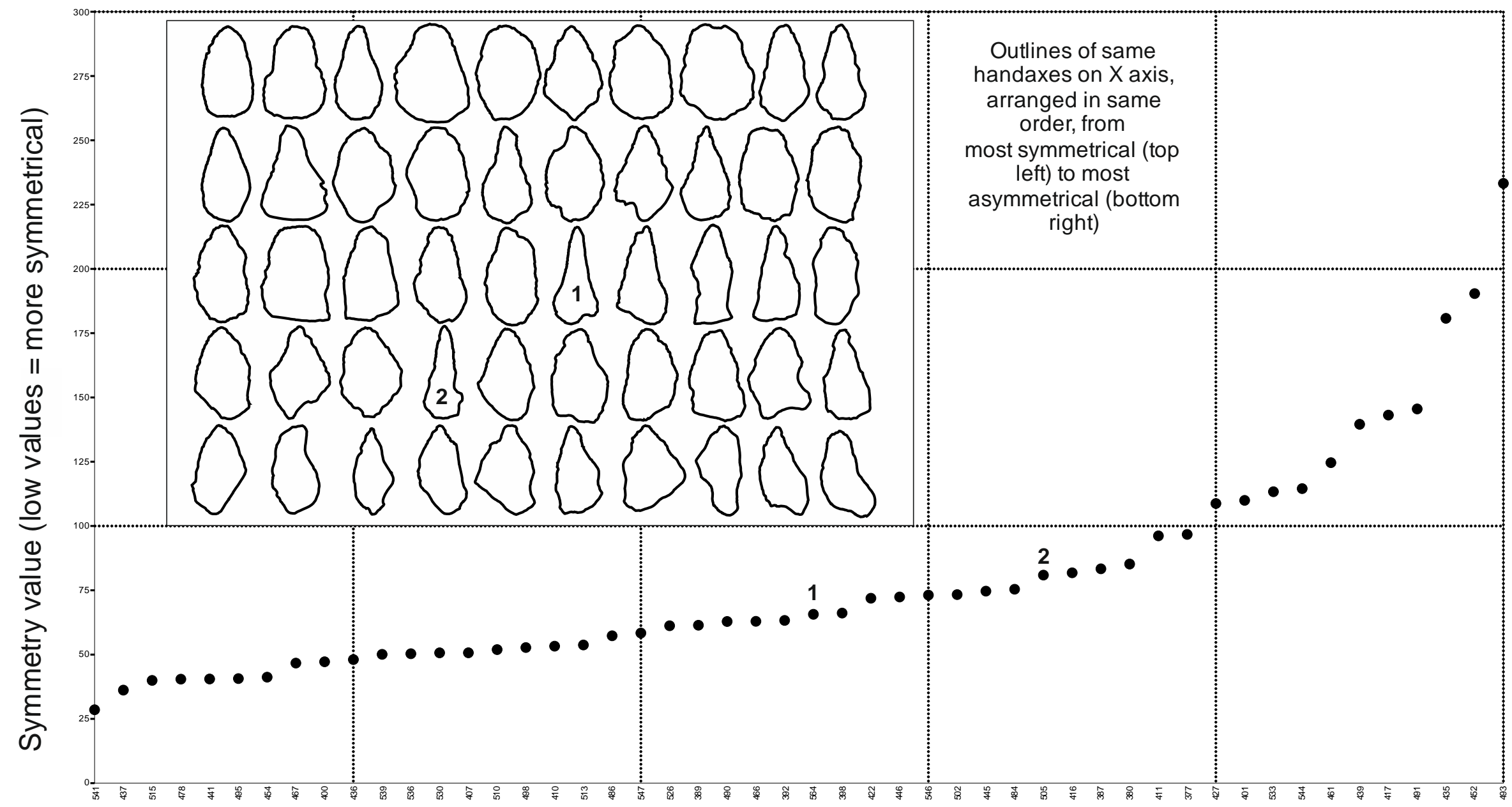

Handaxe numbers from the Marshall et al. database arranged from most symmetrical (left) to most asymmetrical (right) 
Figure 3. Data from 50 randomly sampled handaxes from the Marshall et al. database for the MIS 8/7 site of Cuxton, UK. Photographs of the handaxes were uploaded into CorelDraw 16, their outlines digitised, and calliper measurements added to scale the handaxe's outline to real world sizes. A 10x2 grid was fitted onto the outline (i.e. the length of the handaxe divided into ten equal segments; the width into two halves which represents the axe's midline at $50 \%$ of $\mathrm{W}$, termed here the natural midline). The handaxes were then flipped around the natural midline. The degree of overlap in each segment was then measured. This was the longest distance between the inner outline, and the outer one, measured at right angles to the former in millimetres. Where this analysis differs from McNabb 2012, is that here we summed the segment overlaps and then divided them by the handaxe's total width, multiplying the result by 100 . The measure of symmetry for every handaxe is therefore the total overlap expressed as a percentage of the axe's total width. The smaller the value the greater the symmetry. Axe outlines not to scale. 


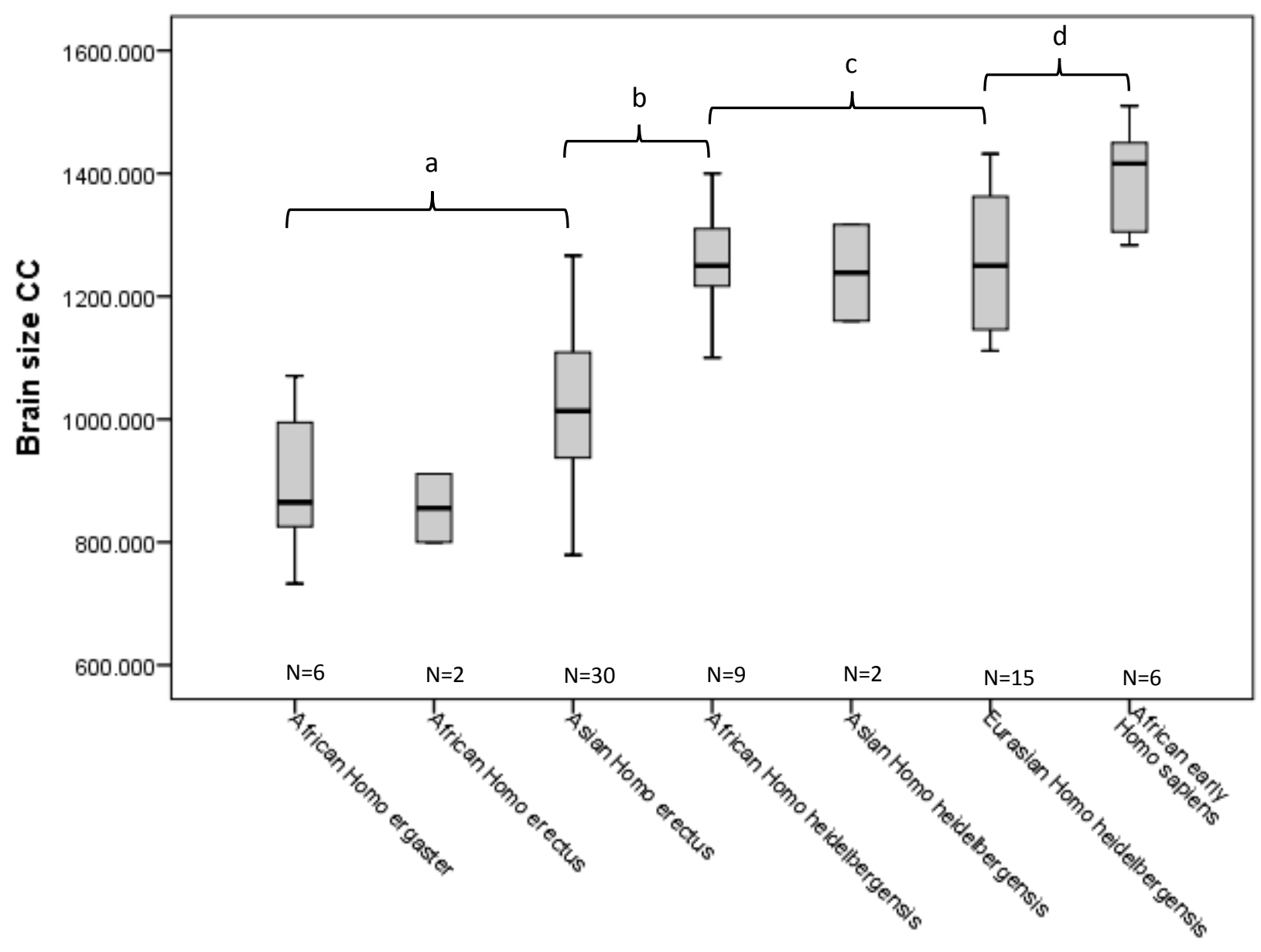

Species/location

Figure 4a. 


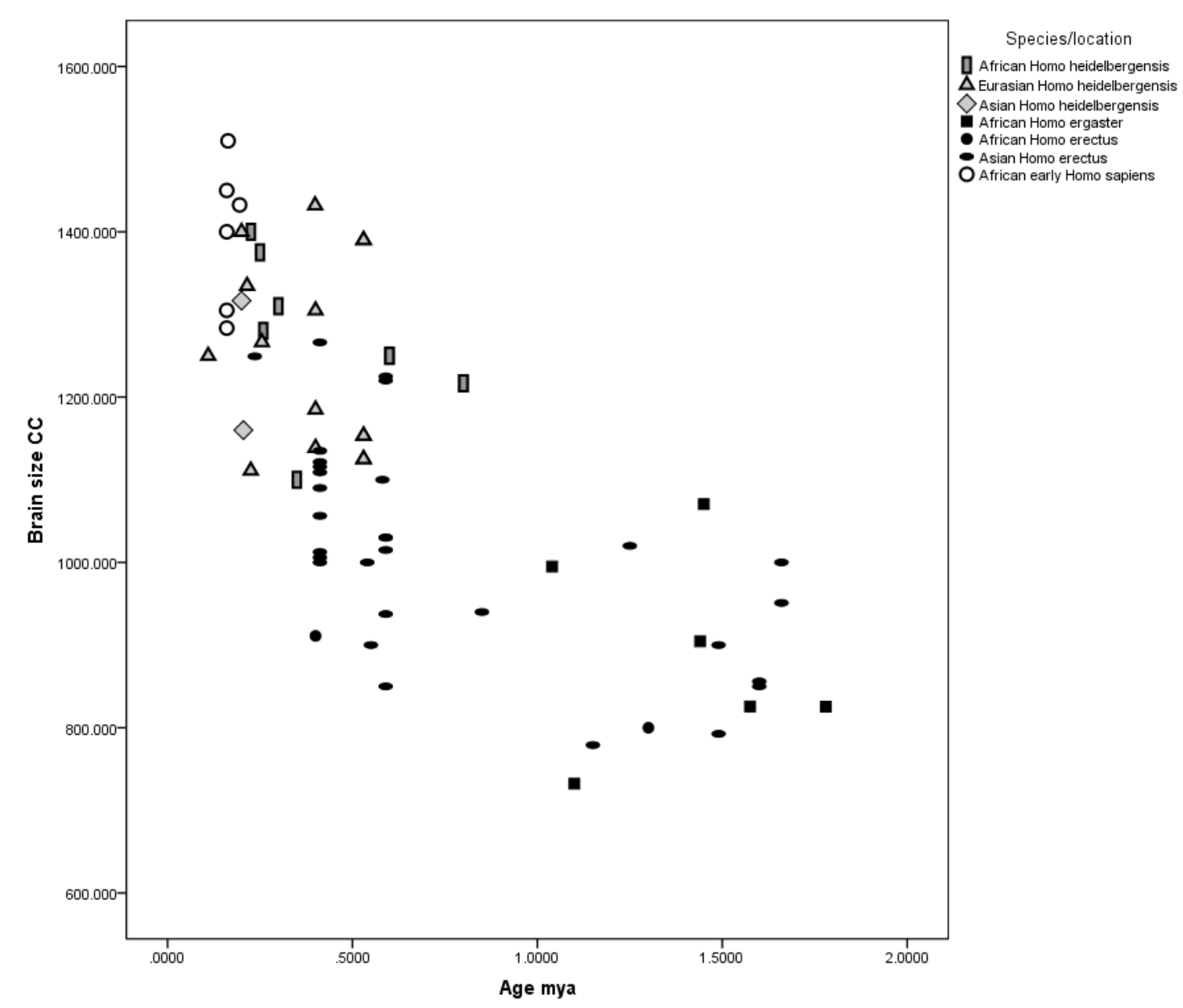

Figure $4 b$

Figure 4.

a) Box and whisker plots showing median and interquartile range of absolute brain size (CC) for handaxe making hominin species. a) statistically significant difference between Homo ergaster and Asian Homo erectus $\mathrm{p}=0.037$ (Mann-Whitney $U$ test), b) statistical difference between Asian Homo erectus and African heidelbergensis is significant $p=0.000$ (MannWhitney $U$ test), c) statistically significant similarity between Eurasian and African Homo heidelbergensis $\mathrm{p}=0.770$ (Mann-Whitney $U$ test), d) statistically significant difference between European Homo heidelbergensis and earliest African Homo sapiens $p=0.011$ (Mann-Whitney U test). Data from table 2 taken from Shultz et al. 2012, see this reference for details. The same pattern is repeated in Gowlett et al. 2012 figure 2, using box and whisker plots based on a different database generated by the Social Brain project. MannWhitney $U$ tests were chosen as appropriate for data were there is no assumption of a normal distribution.

b) Absolute brain size (CC) for individual hominin specimens in table 2 plotted against their suggested ages. Details in Shultz et al. 2012. 


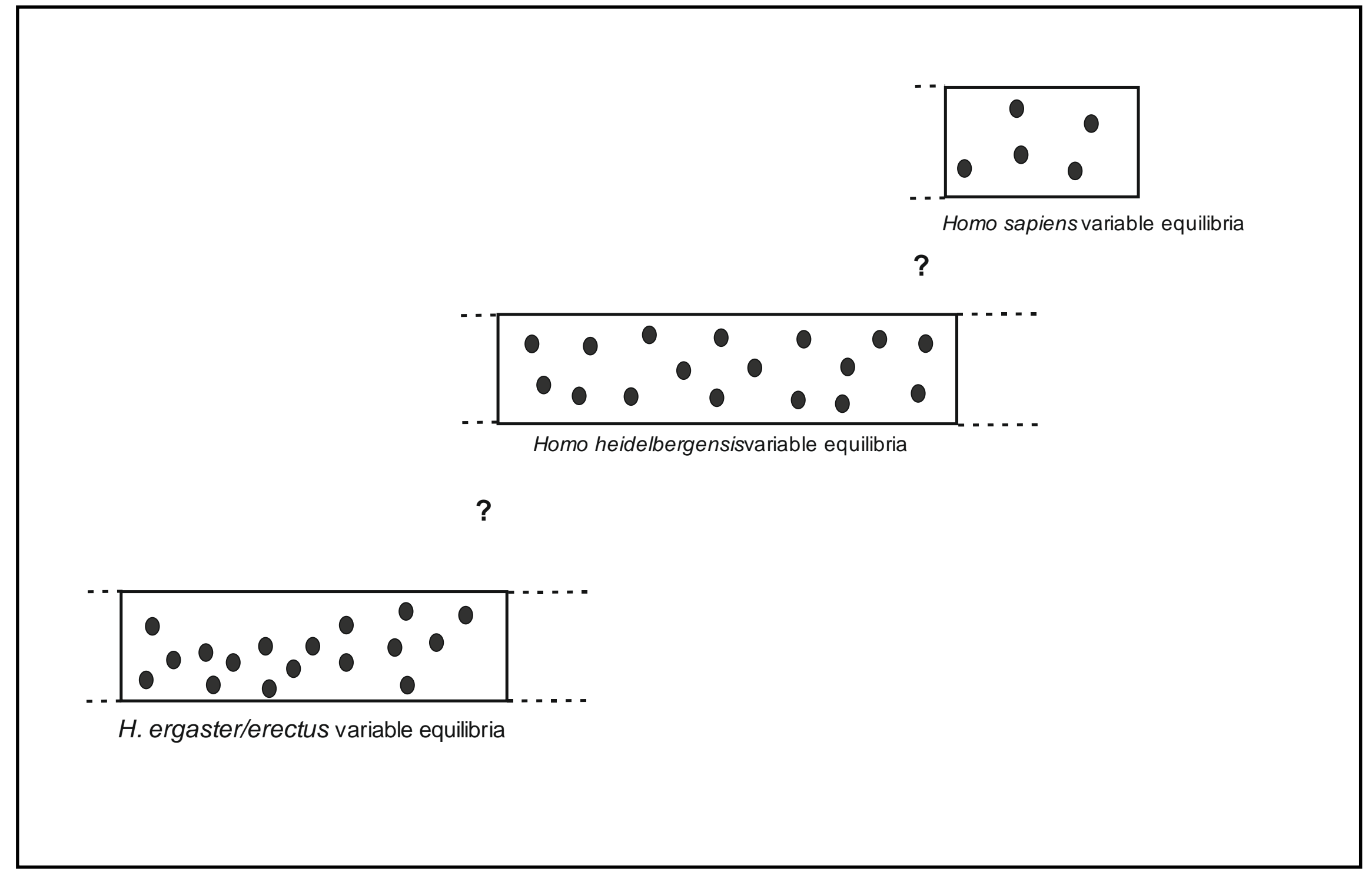


Figure 5. Schematic showing the step-and-stasis model of brain evolution for the handaxe making hominins. The distribution of dots within each horizontal step reflects the variability in brain size seen between differing individuals within species. We describe the variability within each horizontal step as a 'variable-equilibrium'. 


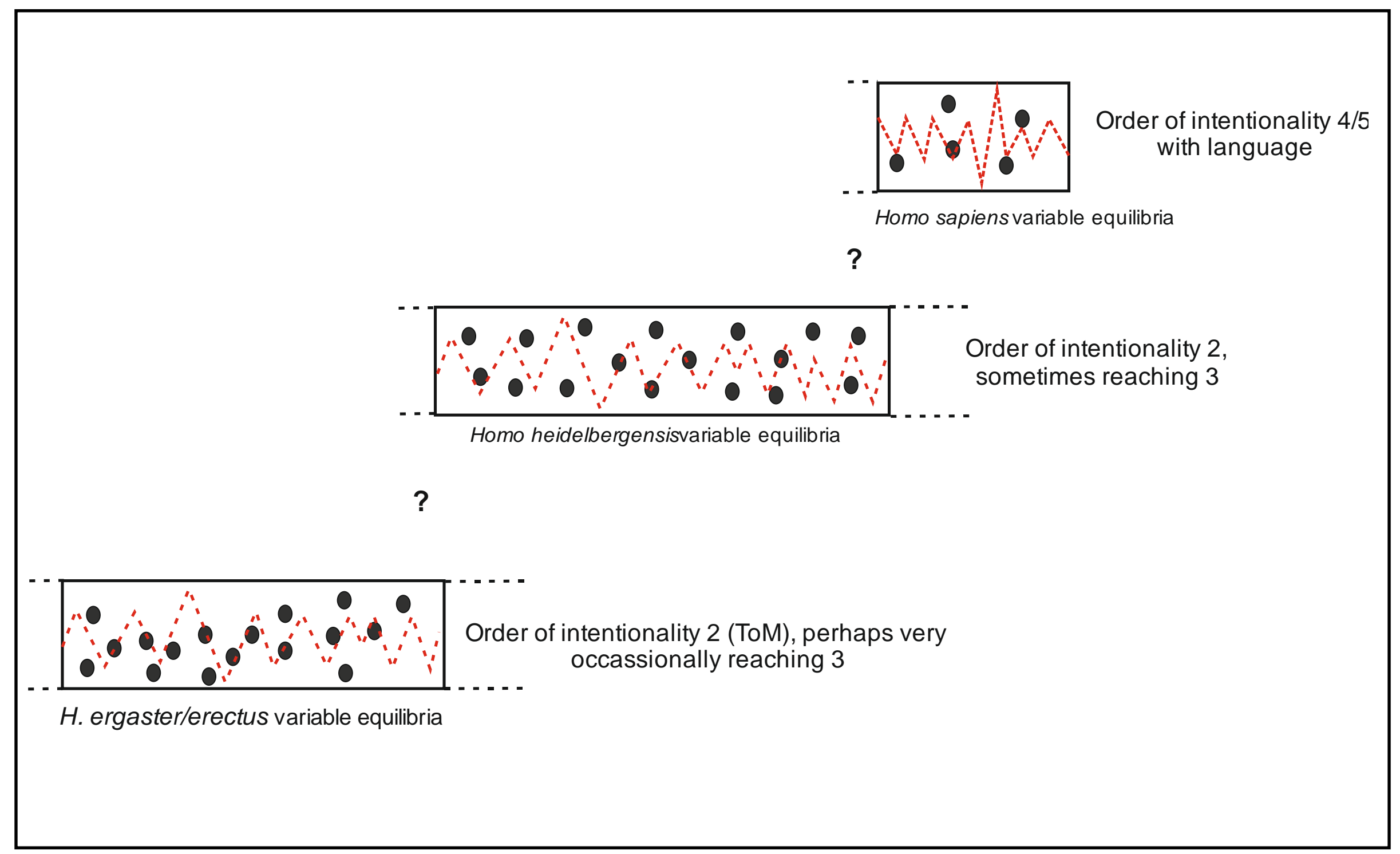


Figure 6. Schematic of step-and-stasis, punctuated variable-equilibria model. The dots in the horizontal steps indicate that hominin brain size can vary considerably within each species, not only between individuals but between populations/groups. The zig zag dotted line shows the variability in finish, refinement and symmetry in handaxes that varies about individuals and groups. 


\begin{tabular}{|c|c|c|c|c|c|c|c|c|c|c|c|c|}
\hline Site and unit & Age & $\begin{array}{l}\text { Number of } \\
\text { handaxes } \\
\text { in this } \\
\text { study }\end{array}$ & $\begin{array}{l}\text { Raw } \\
\text { material }\end{array}$ & Condition & $\begin{array}{l}\text { Mean } \\
\text { of } W / L\end{array}$ & $\begin{array}{l}\text { Mean } \\
\text { of } \\
\text { Th/W }\end{array}$ & $\begin{array}{l}\text { Max. } \\
\text { value } \\
\text { for } \\
W / L\end{array}$ & $\begin{array}{l}\text { Median } \\
\text { value } \\
\text { for } W / L\end{array}$ & $\begin{array}{l}\text { Min. } \\
\text { value } \\
\text { for } W / L\end{array}$ & $\begin{array}{l}\text { Max. } \\
\text { value } \\
\text { for } \\
\text { Th/W }\end{array}$ & $\begin{array}{l}\text { Median } \\
\text { value } \\
\text { for } \\
\text { Th/W }\end{array}$ & $\begin{array}{l}\text { Min. } \\
\text { value } \\
\text { for } \\
\text { Th/W }\end{array}$ \\
\hline Cuxton & MIS 8-7 & 125 & flint & $\begin{array}{l}\text { lightly } \\
\text { abraded }\end{array}$ & 0.58 & 0.58 & 0.84 & 0.6 & 0.34 & 0.89 & 0.57 & 0.33 \\
\hline $\begin{array}{l}\text { Montagu } \\
\text { Cave L3 }\end{array}$ & $\begin{array}{l}\text { Middle } \\
\text { Pleistocene }\end{array}$ & 42 & quartzite & fresh & 0.56 & 0.49 & 0.82 & 0.56 & 0.39 & 0.72 & 0.5 & 0.32 \\
\hline $\begin{array}{l}\text { Cape } \\
\text { Hangklip }\end{array}$ & $\begin{array}{l}\text { Middle } \\
\text { Pleistocene }\end{array}$ & 79 & quartzite & fresh & 0.59 & 0.51 & 0.82 & 0.59 & 0.4 & 0.79 & 0.51 & 0.37 \\
\hline Broom & MIS 9 & 147 & chert & $\begin{array}{l}\text { lightly } \\
\text { abraded }\end{array}$ & 0.64 & 0.43 & 0.98 & 0.66 & 0.41 & 0.75 & 0.42 & 0.29 \\
\hline $\begin{array}{l}\text { Montagu } \\
\text { Cave L5 }\end{array}$ & $\begin{array}{l}\text { Middle } \\
\text { Pleistocene }\end{array}$ & 72 & quartzite & fresh & 0.55 & 0.54 & 0.76 & 0.54 & 0.41 & 0.76 & 0.54 & 0.32 \\
\hline $\begin{array}{l}\text { Sidi } \\
\text { Abderrahman } \\
\text { STIC }\end{array}$ & $\begin{array}{l}\text { Middle } \\
\text { Pleistocene }\end{array}$ & 78 & quartzite & fresh & 0.57 & 0.56 & 0.77 & 0.57 & 0.44 & 0.92 & 0.55 & 0.36 \\
\hline $\begin{array}{l}\text { Warren Hill, } \\
\text { lightly } \\
\text { abraded }\end{array}$ & MIS 13 & 131 & flint & $\begin{array}{l}\text { lightly } \\
\text { abraded }\end{array}$ & 0.71 & 0.39 & 0.99 & 0.74 & 0.45 & 0.65 & 0.38 & 0.25 \\
\hline $\begin{array}{l}\text { Warren Hill, } \\
\text { abraded }\end{array}$ & MIS 13 & 168 & flint & abraded & 0.68 & 0.45 & 1.03 & 0.7 & 0.45 & 0.93 & 0.43 & 0.28 \\
\hline $\begin{array}{l}\text { Olduvai } \\
\text { Gorge HK, } \\
\text { Bed IV }\end{array}$ & $\begin{array}{l}0.83-0.78 \\
\text { mya }\end{array}$ & 115 & quartzite & fresh & 0.61 & 0.51 & 0.9 & 0.59 & 0.45 & 0.77 & 0.51 & 0.3 \\
\hline $\begin{array}{l}\text { Amanzi } \\
\text { Springs }\end{array}$ & $\begin{array}{l}\text { Middle } \\
\text { Pleistocene }\end{array}$ & 79 & quartzite & $\begin{array}{l}\text { lightly } \\
\text { abraded }\end{array}$ & 0.62 & 0.57 & 0.88 & 0.62 & 0.45 & 0.81 & 0.58 & 0.38 \\
\hline Tabun Ed & MIS 10-8 & 51 & flint & fresh & 0.71 & 0.47 & 0.92 & 0.73 & 0.46 & 0.71 & 0.46 & 0.29 \\
\hline Elandsfontein & $1.0-0.6$ mya & 110 & silcrete & fresh & 0.62 & 0.54 & 0.92 & 0.63 & 0.46 & 0.76 & 0.53 & 0.3 \\
\hline Doornlaagte & c. $1.0 \mathrm{mya}$ & 30 & andesite & $\begin{array}{l}\text { lightly } \\
\text { abraded }\end{array}$ & 0.54 & 0.55 & 0.66 & 0.54 & 0.46 & 0.73 & 0.54 & 0.43 \\
\hline
\end{tabular}




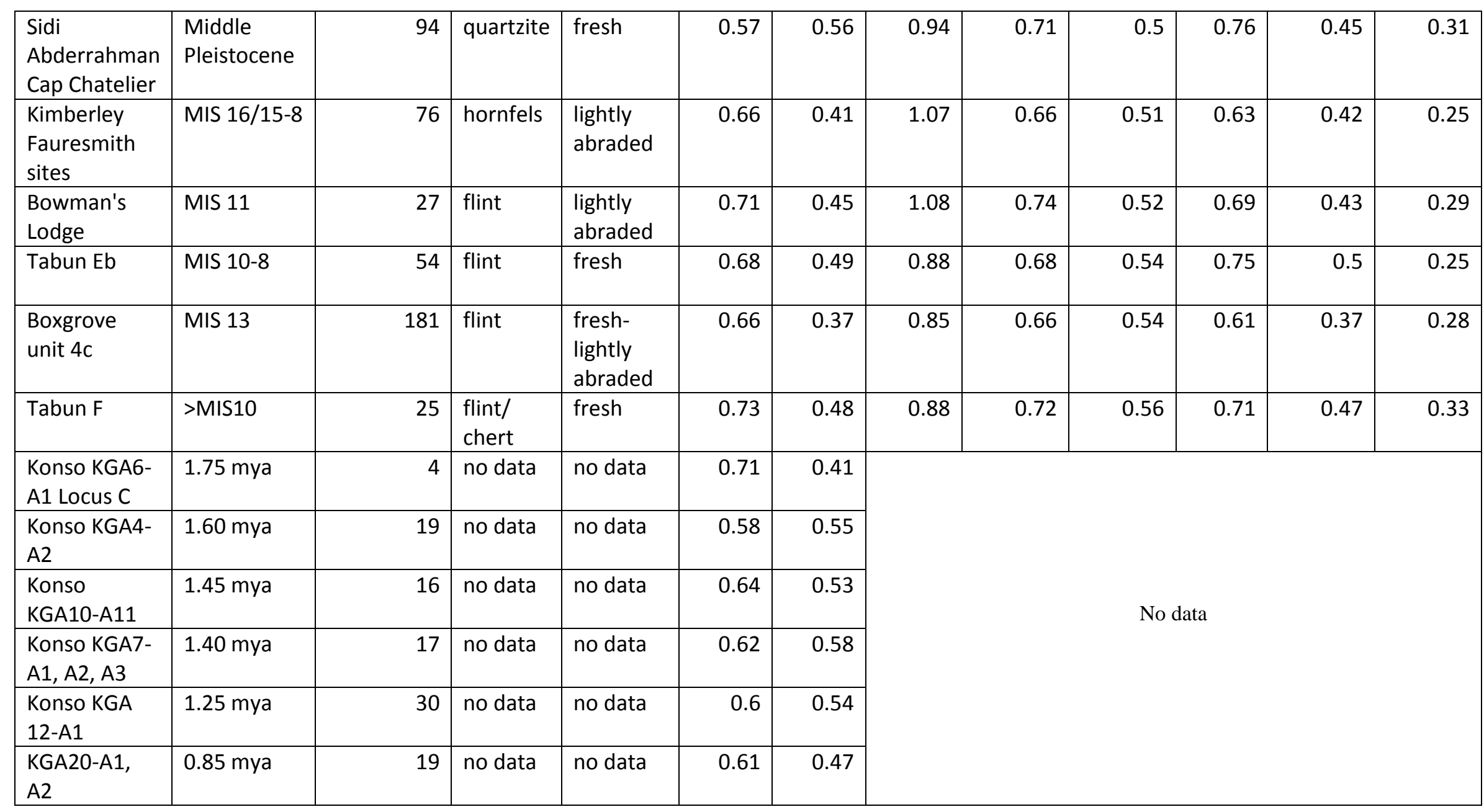


Table 1. Data for sites, sample sizes and contexts used in figures 1 and $2 \mathrm{a} / 2 \mathrm{~b}$. Data and age ranges and broader discussion of sites in McNabb 2005, 2007, 2013, Marshall et al. 2002, Matskevitch 2006, Beaumont and Vogel 2006, Bayene 2013. For these data, only complete handaxes used. All handaxes were also selected to be in the same raw material and in the same condition. This increases the likelihood of sample integrity. The advantage of the Marshal et al database is that all measurements and observations were taken by one individual (Marshall) therefore increasing confidence in comparability in data between assemblages. One of us (JM) revised the condition of Boxgrove and Bowman's Lodge on the basis of familiarity with these assemblages. 


\begin{tabular}{|c|c|c|c|}
\hline $\begin{array}{l}\text { Species and } \\
\text { geographical location }\end{array}$ & Specimen/site & Age in mya & Cranial capacity (cc) \\
\hline \multirow[t]{6}{*}{ African Homo ergaster } & Daka & 1.04 & 995 \\
\hline & $\mathrm{OH} 12$ & 1.1 & 732.33 \\
\hline & KNM-WT 15000 & 1.44 & 904.5 \\
\hline & $\mathrm{OH} 9$ & 1.45 & 1070.5 \\
\hline & KNM-ER3883 & 1.575 & 825.667 \\
\hline & KNM-ER 3733 & 1.78 & 825.4 \\
\hline \multirow[t]{2}{*}{ African Homo erectus } & Salè 1 & 0.4 & 911 \\
\hline & Buia & 1.3 & 800 \\
\hline \multirow[t]{30}{*}{ Asian Homo erectus } & Narmada 1 & 0.236 & 1249.333 \\
\hline & Hexian PA 830 & 0.412 & 1012.5 \\
\hline & Ngandong 1 & 0.412 & 1121.429 \\
\hline & Ngandong 10 & 0.412 & 1109 \\
\hline & Ngandong 5 & 0.412 & 1266.167 \\
\hline & Ngandong 6 & 0.412 & 1115.714 \\
\hline & Ngandong 9 & 0.412 & 1135 \\
\hline & Ngandong 11 & 0.412 & 1090 \\
\hline & Ngawi & 0.412 & 1000 \\
\hline & Sambungmacan 1 & 0.412 & 1056.333 \\
\hline & Sambungmacan 4 & 0.412 & 1006 \\
\hline & Nanjing & 0.54 & 1000 \\
\hline & Poloyo 1 & 0.55 & 900 \\
\hline & Yunxian EV9002 & 0.581 & 1100 \\
\hline & Zhoukoudian II & 0.59 & 1030 \\
\hline & Zhoukoudian III & 0.59 & 937.5 \\
\hline & Zhoukoudian V & 0.59 & 1220 \\
\hline & Zhoukoudian VI & 0.59 & 850 \\
\hline & Zhoukoudian X & 0.59 & 1225 \\
\hline & Zhoukoudian XI & 0.59 & 1015 \\
\hline & Zhoukoudian XII & 0.59 & 1030 \\
\hline & Trinil 2 & 0.85 & 940 \\
\hline & Lantian 1 & 1.15 & 779 \\
\hline & Sangiran 17 & 1.25 & 1020 \\
\hline & Sangiran 2 & 1.49 & 792.571 \\
\hline & Sangiran 3 & 1.49 & 900 \\
\hline & Sangiran 4 & 1.6 & 856 \\
\hline & Sangiran 9 & 1.6 & 850 \\
\hline & Sangiran 12 & 1.66 & 951 \\
\hline & Sangiran 31 & 1.66 & 1000 \\
\hline \multirow{5}{*}{$\begin{array}{l}\text { African Homo } \\
\text { heidelbergensis }\end{array}$} & KNM-ER 3884 & 0.2255 & 1400 \\
\hline & KNM-ES 11693 & 0.25 & 1375 \\
\hline & Florisbad 1 & 0.259 & 1280 \\
\hline & Kabwe & 0.3 & 1310 \\
\hline & Ndutu 1 & 0.35 & 1100 \\
\hline
\end{tabular}




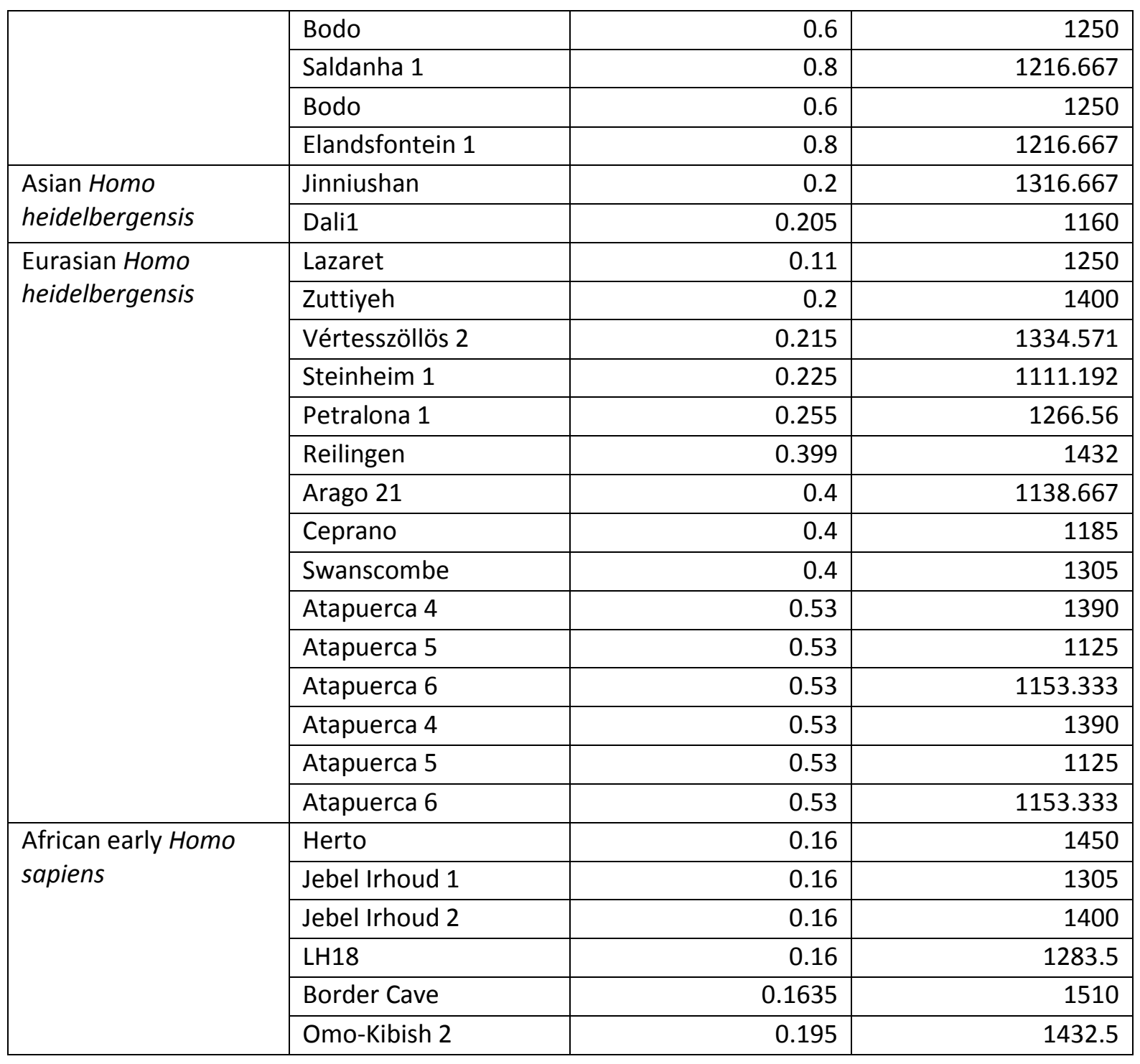

Table 2. Data used to construct box and whisker plots and scattergram in figure 4. Table shows absolute brain size for individual specimens from within different species as found in different locations. Israel is included in Eurasia. India, China and Indonesia are included in Asia. Data from Shultz et al. 2012, see this reference for more details and sources. Some researchers include Swanscombe and Atapuerca (Eurasia) as earliest Neanderthals, here they are included within $H$. heidelbergensis. 